\title{
ECONOMIC SCENARIO GENERATORS AND SOLVENCY II
}

\author{
BY E. M. VARNELL \\ [Presented to the Institute of Actuaries, 23 November 2009]
}

\begin{abstract}
The Solvency II directive mandates insurance firms to value their assets and liabilities using market consistent valuation. For many types of insurance business Economic Scenario Generators are the only practical way to determine the market consistent value of liabilities. The directive also allows insurance companies to use an internal model to calculate their solvency capital requirement. In particular, this includes use of ESG models. Regardless of whether an insurer chooses to use an internal model, Economic Scenario Generators will be the only practical way of valuing many life insurance contracts. Draft advice published by CEIOPS requires that insurance firms who intend to use an internal model to calculate their capital requirements under Solvency II need to comply with a number of tests regardless of whether the model (or data) is produced internally or is externally sourced. In particular the tests include a Use Test, mandating the use of the model for important decision making within the insurer. This means that Economic Scenario Generators will need to subject themselves to the governance processes and that senior managers and Boards will need to understand what Economic Scenario Generator (ESG) models do and what they don't do. In general, few senior managers are keen practitioners of stochastic calculus, the building blocks of ESG models. The paper therefore seeks to explain Economic Scenario Generator models from a non-technical perspective as far as possible and to give senior management some guidance of the main issues surrounding these models from an ERM/Solvency II perspective.
\end{abstract}

\section{KEYWORDS}

Solvency II, Economic Scenario Generator, Governance, Economic Assumptions, Enterprise Risk Management, Market Consistent Valuation, Economic Capital, Regulatory Capital

\section{CONTACT ADDRESS}

E. M. Varnell, MSc. F.I.A., KPMG LLP, One Canada Square, London E14 5AG, U.K. Tel: +44(0)207311-5043; Fax: +44(0)20-7694-2340; e-mail: elliot.varnell@kpmg.co.uk.

\section{INTRODUCTION}

\subsection{Solvency II Background}

1.1.1. On 5 May 2009, the Economic and Financial Affairs Council, comprising the Economic and Finance ministers of the European Union, agreed to adopt the Solvency II Directive. In addition to its adoption in the European Union, supervisory regimes with similar features to Solvency II appear likely to be widely adopted around the globe. At the time of writing, Chile and Mexico had decided to pursue Solvency II style insurance regulation while other countries, including Japan and Taiwan are understood to also be considering Solvency II style proposals. Switzerland in particular has already adopted a Solvency II style regulatory regime; the Swiss Solvency Test.

1.1.2. The Solvency II Directive is known as the Level 1 text, after the Lamfallusy Process. After the directive was agreed the next stage was to define the Level 2 Implementing Measures which provide much of the technical detail on how Solvency II will work. The Committee of European Insurance and Occupational Pensions 
Supervisors CEIOPS were asked to provide advice on what the Implementing Measures should be.

1.1.3. Consequently, during 2009, CEIOPS have issued a number of papers setting out their view of what the Level 2 implementing measures should be. These papers contain the advice that CEIOPS propose to present to the European Commission early in 2010. They represent the best reference for what the detail of Solvency II will look like.

1.1.4. This paper makes frequent reference to CEIOPS Consultation Papers. They are referred by their number, for example ' $\mathrm{CP} 40$ '. All the papers can be found on the CEIOPS website and links are provided at the end of this paper.

\subsection{Aim of the paper}

1.2.1. The purpose of this paper is to discuss the use of Economic Scenario Generators (ESG models) in the context of Solvency II. While much has been written about Solvency II, little has been written to explain specifically how ESG models will be used under Solvency II and what issues will need to be considered. This paper aims to take the broad themes covered by Solvency II and discuss how ESG models fit into them.

1.2.2. ESG models are a potentially very broad subject and could include many details on model design, methods for choosing economic assumptions and techniques for improving the efficiency of economic scenarios. Furthermore, the Solvency II Implementing Measures cover a very broad range too and a lot of detail could be covered in a paper such as this. However, to keep the paper relatively short and accessible to those not seeking technical detail, this paper aims to keep the discussion at a reasonably high level.

1.2.3. The Solvency II Directive makes it clear that complex mathematics or software tools are no substitute for genuine understanding of what drives risk within an insurance company. Senior managers and boards are going to need to understand what functions ESG models perform. However, few senior managers are currently close to the required levels of understanding. Much material on the subject of ESG models is by necessity, technical, and can therefore be quite difficult to assimilate for a nontechnical manager. This paper has therefore steered away from the technical detail and formulae in an attempt to focus on the key issues and considerations for the effective use of ESG models in the post Solvency II environment.

1.2.4. In this paper the word 'scenarios' is used to refer to stochastically generated economic simulations using a Monte-Carlo driven model. By contrast elsewhere in the risk management literature, scenarios can be used to mean a comparatively small number of possible future outcomes that are used as part of the risk management process.

\subsection{Layout of the paper}

In Section 2, some of the main drivers external to the firm for the use of ESG models are discussed. Notwithstanding that Market Consistent Valuation is mandated in the Solvency II Directive, it has been criticised by some as a contributory factor to the Global Financial Crisis. In Section 3, the question of why Market Consistent Valuation is used and its advantages and disadvantages are discussed. In Section 4, the paper considers why insurers would use an ESG model for the market consistent valuation of their liabilities. Also considered are some alternative approaches. In 
Section 5, the paper focuses on market consistent valuation in more detail and discusses some of the products that lend themselves to Market Consistent Valuation. In Section 6, the paper discusses the role of the ESG model in a Solvency II Internal Model. In Section 7, the paper discusses how ESG models interact with Pillars 2 and 3 and in particular how ESG models interact with the governance of an insurance company.

\section{APPLICATIONS OF ESG MODELS}

\subsection{Solvency II}

2.1.1. The Directive mandates market consistent valuation for all insurance business and gives the opportunity to use an internal risk model for the calculation of the solvency capital requirement. ESG models are a key element of market consistent valuation for life insurance business and an important tool for measuring and managing market and credit risk in an internal model.

2.1.2. Although the twin concepts of market consistent valuation and internal models in Solvency II have been driving much recent interest in Economic Scenario Generators, it is worth briefly mentioning some other drivers for their use in the Insurance sector.

2.1.3. These include:

- rating agency criteria;

- local regulations;

- reporting standards; and

- other uses.

\section{2. $\quad$ Rating Agency Criteria}

Some rating agencies have introduced additional rating criteria for Enterprise Risk Management (e.g. Standard \& Poors 2007) and have considered the use of market consistent valuation and stochastic economic scenarios for determining economic capital requirements to be good practice for demonstrating risk and capital management.

\subsection{Local Regulations}

2.3.1. Even before Solvency II was agreed in Spring 2009, there were several local regulatory regimes in Europe and elsewhere in the world where ESG models have been a key tool for the calculation of regulatory returns and information provided to regulators. These include the following countries: United Kingdom (U.K.), Switzerland and South Africa.

\subsection{Local Regulations - U.K.}

2.4.1. In the U.K., the Pillar 1, Peak 2 Realistic Balance Sheet (RBS) has required market consistent valuation of participating life assurance business. ESG models have been widely used for undertaking this market consistent valuation.

2.4.2. In the U.K., Pillar 2 Individual Capital Assessment (ICA) regulation companies are required to assess the amount of capital they require to withstand a 1 in 200 event over 1 year. ESG models have be used for measuring this stress test in respect of market and credit risk. 


\subsection{Local Regulations - Switzerland}

In Switzerland, the Swiss Solvency Test (SST) market consistent valuation is required for the valuation of traditional life assurance business and ESG models have been used for this valuation. The SST also permits the use internal models. ESG models have also be used in internal models for the calculation of regulatory capital, for example in the calibration and projection of replicating portfolios.

\subsection{Local Regulations - South Africa}

In South Africa, the PGN-110 Actuarial Guidance Note requires the market consistent valuation of participating life insurance business. ESG models have been used for this and can also be used for the calculation of the capital adequacy requirement (CAR) risk capital calculation in a similar way to their use in the U.K. ICA.

\subsection{Reporting Standards - CFO Forum}

2.7.1. European Embedded Value (EEV) is often calculated using real world stochastic projections from an ESG model, along with the certainty equivalent approach to capturing the approximate time value of options and guarantees.

2.7.2. In October 2009, the CFO Forum issued revised Market Consistent Embedded Value (MCEV) principles. These usually necessitate the use of a market consistent (risk-neutral) ESG model for participating life business, except where a closed form is sufficiently accurate. The revised principles include two principles of direct relevance to ESG models. Principle 15 specifically covers the calibration and use of ESG models. Principle 14 covers the choice of reference rate; an input to the ESG model calibration.

\subsection{Other Uses}

2.8.1. Early versions of ESG models were not used for prudential supervision, but in the area of Insurance Asset Liability Management (ALM), and Life Insurance product design. ESG models are still used in these areas today and are now also being used in other areas of insurance companies. For example:

- The communication of the risks and rewards associated with retail insurance products.

- The dynamic hedging of individual insurance products or dynamic hedging of a book of insurance liabilities.

- The management of assets backing insurance liabilities.

- The asset liability management of pension schemes.

\subsection{Types of ESG Scenarios used in Solvency II}

2.9.1. It is worth mentioning that there are two types of ESG scenarios which could be used for compliance with Solvency II.

2.9.2. The first of these are market-consistent scenarios. These are used for market consistent valuation in Solvency II. These scenarios have the main objective of reproducing market prices. They are typically designed to be risk-neutral (zero risk premium), as this facilitates the calculation but does not generally influence the valuation. The models used tend to be banking-style models and calibration of volatility is typically to option price implied volatility. 
2.9.3. The second type of ESG scenario set are real-world scenarios which aim to produce realistic economic scenarios that reflect the way the world is expected to evolve by the insurer. These models can be based on quantitative banking models, in which case similar models to those used for market consistent calibration are used, albeit with a slightly different calibration. A wider set of models is also possible, including econometric models or bootstrapping models. Real world ESG models will not necessarily be arbitrage-free however, and therefore care needs to be taken in their use.

2.9.4. Real world models invariably include risk premia. Some models, such as deflator oriented models, are able to combine quantitative banking models with risk premia, although calibration to different volatilities is required if the same model produces real-world and market consistent scenarios. For example, market equity implied volatilities which are used in the calculation of technical provisions are usually higher than the realised standard deviation of returns which are used to calibrate a real world ESG models. Using equity implied volatility as a proxy for the real world equity volatility in the SCR calculation may be considered penal. This is because insurers would then import the additional margins which investment banks add to long term implied volatility into their volatility estimates and therefore into their capital requirements. The banks add extra margins to cover: hedging costs; the banks' cost of capital; and liquidity risk. It is not evident that insurers should hold capital for these risks.

2.9.5. The remainder of this paper discusses both types of model. In sections 3, 4 and 5 , market consistent valuations and the use of ESG models in market consistent valuations is discussed. Section 6 discusses internal models and therefore the focus is mainly on the use of ESG models for real world projection. The final section on governance applies to both market consistent and real world applications of ESG models.

\section{WHY MARKET CONSISTENT VALUATION?}

\subsection{Introduction}

3.1.1. For most EU countries and insurers, market consistent valuation will represent a dramatic change to the way in which their balance sheet is constructed. This section considers why it is appropriate for insurers to use market consistent valuation of their liabilities. The simple answer is that the Solvency II Directive mandates market consistent valuation and so the question of whether it is appropriate is irrelevant.

3.1.2. However, this is a topic worth discussing, because in the wake of the recent Global Financial Crisis, market consistent valuation within the banking sector has been criticised as a contributory factor to the crisis. This has caused some to question the wisdom of introducing market consistent valuation into insurance solvency regulation when accounting standards and other regulatory initiatives are questioning the relevance of market consistent valuation.

3.1.3. In the following section, five common misconceptions regarding market consistent valuation are explored. 


\subsection{Misconception 1: An Arbitrage Free ESG Model will by Itself give a Market Consistent Valuation.}

3.2.1. There are two key ingredients to a market consistent valuation; an arbitrage free ESG model and calibration to deep and liquid market data. Both are required in order to carry out a market consistent valuation.

3.2.2. However, at the time of writing there is no agreed definition of what constitutes deep and liquid market data in Solvency II and therefore there is no agreed definition of what constitutes market consistent valuation.

3.2.3. Furthermore, where data is illiquid or unavailable, such as for very long term option prices, it is not possible to have a market consistent valuation. In CP41, CEIOPS go so far as to say that a market data must be permanently deep and liquid. This appears to exclude the possibility of a market consistent valuation using any data which could become illiquid, which could include all markets.

3.2.4. Given that, much of the data within an ESG model calibration will not be available from deep and liquid market data, some workarounds are required.

3.2.5. CEIOPS' current solution (set out in CP42) is to use best estimate data and to apply the cost of capital risk margin where a deep and liquid data is unavailable.

3.2.6. An alternative, which is not currently favoured by CEIOPS, but which is widely used in practice, is to use economic theory to infer what prices would trade at, based on economic theory and then to calibrate to these prices.

3.2.7. Another possible solution lies in CP39, which appears to leave open the question of whether historic or implied volatility should be used for market consistent volatility. Orthodox finance theory would simply answer that implied volatilities should be used, as anything else would not be market consistent. However, CP39 suggests historic volatilities (presumed also to be best estimate volatilities), could be used without a cost-of-capital risk margin being applied.

\subsection{Misconception 2: A Model calibrated to Deep and Liquid Market Data will give a Market Consistent Valuation.}

3.3.1. A model calibrated to deep and liquid market data will only give a market consistent valuation if the model is also arbitrage free. If a model ignores arbitrage free dynamics, then it could still be calibrated to replicate certain prices. However, this would not be a sensible framework for the valuation of other assets and liabilities.

3.3.2. An important feature of an arbitrage model is that it can price assets and liabilities not included in the ESG model calibration data in an economically coherent way. 'Economically coherent' means that the cash-flows from the asset (or liability) will be priced exactly the same, regardless of which assets or strategies were used to generate the cash-flows. It is not always evident that a model is arbitrage free. In fact, to be arbitrage free, a model must fulfil certain mathematical criteria which are beyond the scope of this paper. See Wilmott, (2001) for more details.

\subsection{Misconception 3: Market Consistent Valuation gives the right valuation.}

3.4.1. Market consistent valuation does not give the right answer, per se, but $a$ valuation conditional on the model and the calibration parameters. The valuation is only as good as these underlying assumptions. Assumptions are needed because there is not enough deep and liquid market data to calibrate a usable ESG model. One thing which is certain is that the model will be wrong in some way. 
3.4.2. For this reason, understanding and documenting the assumptions and weakness of an ESG model and its calibration is as important as the ESG model design and ESG model calibration.

\subsection{Misconception 4: Market Consistent Valuation gives the Amount that a 3rd Party will pay for the Business.}

3.5.1. Market Consistent Valuation, (as calculated using an ESG) gives a value based on pricing at the margin. As with many financial economic models, the model is designed to provide a price based on a small scale transaction, ignoring trading costs, and market illiquidity. The assumption is made that the marginal price of the liability can be applied to the entire balance sheet. Separate economic models are required to account for micro-market features; for example the illiquidity of markets or the trading and frictional costs inherent from following an (internal) dynamic hedge strategy. Micro-market features can be most significant in the most extreme market conditions; for example, a typical 1-in-200 stress event or 2008.

3.5.2. Even allowing for the micro-market features, a transaction price will account for the hard to value assets (e.g. franchise value) or hard to value liabilities (e.g. contingent liabilities). It is likely that the valuation of hard to value assets and liabilities will take place in a much less quantitative manner than using an ESG model.

\subsection{Misconception 5: Market Consistent Valuation is no more objective than a traditional Discounted Cash Flow (DCF) technique, using long term subjective rates of return.}

3.6.1. The previous myths could have suggested that market consistent valuation is in some way devalued or not useful. This is certainly the viewpoint of some, in the light of the recent financial crisis. However, it can equally be argued that market consistent valuation, if done properly, gives a more economically meaningful value and provides better disclosure, than traditional DCF.

3.6.2. Market consistent value provides an improved breakdown by decomposing the valuation into clear assumptions about what economic theory is being applied and clear assumptions regarding the calibration parameters. By breaking down the models and assumptions in this way, invalid assumptions and weaknesses of the economic theory are more readily identified .

\subsection{Criticism of Market Consistent Valuation}

3.7.1. Critics of market consistent valuation argue that it causes a dangerous procyclical feedback loop in the economy. This appears to have been borne out during the recent crisis, as liabilities rise due to increased implied volatility, lower government bond interest rates, and an increase in the moneyness of put options. At the same time, asset values (usually with the exception of government debt), fall markedly. The net result is that capital levels are squeezed from both directions, further depressing the share prices and corporate debt prices. This in turn further lowers the assets side of the balance sheet held by financial institutions. This has been particularly noticeable in banks where high leverage is typical. However, this also affects the insurance sector too, albeit to a lesser extent due to lower levels of leverage.

3.7.2. Market consistent valuation has also been criticised because it provides risk management incentives to sell risky assets during stressed market conditions, in order to improve solvency. However, this further depresses the prices of assets which causes solvency to deteriorate further. 
3.7.3. An economically based regulatory regime which mandates a high and constant degree of policyholder protection regardless of the prevailing economic conditions would inevitably be pro-cyclical, because a crisis such as 2008 inevitably weakens the capital position of an insurer. The 'Solvency II Pillar 2 Dampener' as set out in CP64 is an acknowledgement of the need for flexibility in this regard.

3.7.4. Alternative techniques to market consistent valuation usually involve traditional DCF methods using a constant, subjectively chosen discount rate. It has been suggested that such approaches can indicate whether markets are over or under valued at any point in time. This has some appeal shortly after a crash, because the argument that the long term valuation of markets was in fact lower than the actual market just before the crash is intuitive. However, such approaches tend to work better with hindsight and still appear unable to say when a market will correct. During a bubble, such models can suggest that a market is overvalued but they find it difficult to distinguish between a speculative bubble and a fundamental shift in the valuation

3.7.5. Traditional DCF techniques can have a role in the asset management departments in strategic asset allocations. However, they are not able to give values which reconcile to the prices which one actually needs to pay in a market. Of course above, it is argued that market consistent valuation does not do this either. However, this paper argues that building the economic value of insurance liabilities using economic theory and clearly articulated economic assumptions will deliver a valuation more highly correlated with market values than other methods, such as traditional DCF.

3.7.6. Notwithstanding the comments on DCF techniques, this paper does not argue that the probability of an imminent crash cannot be inferred through other techniques. For example, attempts within various economies globally to collect aggregate information on derivative positions in order to spot systemic imbalances could well provide advance warning of future problems due to the fact they would contain private information about positions.

\subsection{Liquidity Premia}

3.8.1. There is currently much debate about the existence and quantification of liquidity premia. The economic models typically deployed for market consistent valuation in ESG models ignore micro-market features such as shallow markets, illiquid markets and bid-offer spread. Each of these factors can be considered to contribute in some measure to a liquidity premium. By ignoring these features, market consistent ESG models implicitly ignore liquidity premia. Different models, external to the ESG model, are typically used to quantify liquidity premia.

3.8.2. The debate so far has focused on liquidity premia for risk free rates. This is understandable given the importance of this economic variable to all valuation and the relative ease of quantifying the liquidity premium on fixed interest asset classes as compared to other asset classes.

3.8.3. Liquidity premia are relatively easy to measure for fixed interest securities. This is because it is easier to identify two securities which pay out the same cash-flows under all circumstances. The liquidity premium is the difference in price between two instruments which differ only in their degree of liquidity. By contrast, liquidity premia are also suspected to exist on smallcap equities, but finding any security which pays the same cash-flows as particular smallcap equity under all circumstances is much more challenging. This is not to suggest that estimating liquidity premia on fixed 
interest securities is straightforward. A literature survey of recent academic work done on liquidity premia is Hibbert et al, (2009) illustrates that different academic studies show a great diversity between the estimates.

3.8.4. However, liquidity premia could equally well exist on other market variables, such as equity implied volatility. As discussed above, CEIOPS have tried to deal with this issue in CP42 by excluding illiquid data from market consistent valuation.

3.8.5. When using an ESG model, it is important to recognise that it will apply orthodox finance theory, and liquidity premia will only be reflected to the extent that they are reflected in the ESG model calibration parameters, such as the risk free rate or the equity implied volatility.

3.8.6. The application of different liquidity premiums to different product groups raises some interesting practical issues for ESG model usage. For example, it may be necessary to run different ESG model calibrations for different product groups.

\section{WHY USE A MONTE CARLO ESG MODEL FOR VALUATION?}

\subsection{Introduction}

4.1.1. This section of the paper considers why insurers would use an ESG model for the market consistent valuation of their liabilities and discusses some alternative approaches.

4.1.2. Many of the uses of ESG models are in the calculation of a market consistent value for complex life insurance policies, where the assets and liabilities are not well matched. Typically, these will be participating policies with management actions and policyholder actions directly impact on the cash-flows paid. ESG models use a Monte Carlo technique to come up with a valuation for these policies.

4.1.3. However, Monte Carlo valuation is not a particularly convenient method to use, as it requires many scenarios to be run. Monte Carlo valuation is also subject to sampling error, which can be significant. Based on the U.K. and Swiss experience, it is typical for an insurer to use between 2,000 and 5,000 scenarios when calculating a market consistent valuation of liabilities for a typical portfolio of participating insurance liabilities.

4.1.4. Life insurers also have to calculate a valuation for many thousands of policies over a long time horizon. The cash-flows on these policies often have complex interactions with management and policyholder behaviour. Consequently, the full policy portfolio has to be condensed to, typically, 5,000 to 15,000 representative contracts (model points), in order to produce valuations within reasonable timescales.

4.1.5. New solutions based technologies, such as Grid and Cloud Computing, are starting to emerge in the insurance industry which should enable runtimes to reduce and/or allow more scenarios or representative contracts to be run.

\subsection{Closed-Form Solutions}

4.2.1. It is quicker and more convenient to use a closed-form formula to calculate a market consistent value. The most obvious example of such a formula is the vanilla Black-Scholes-Merton European option price formula. Generally, the valuation of a vanilla European option would not be done using an ESG model, as the formula is much more convenient and option implied volatilities are readily available from market data providers.

4.2.2. Many other formulae have been developed which incorporate features such as: 
- Mixed underlying asset portfolios (basket options).

- Digital features such as barrier options (down and out, up and in).

- Options on options.

4.2.3. There is a rich set of closed form option formulae which one can consider and some authors have also developed closed form formulae to approximate life insurance liabilities (Sheldon et al., 2004, Wilkie, 2002). Therefore, it is not obvious that an ESG model is needed to value insurance policy liabilities in a market consistent way.

4.2.4. In practice however, these formulae have not found widespread use for the calculation of market consistent values because of several issues:

- Many insurance liabilities are options on an underlying mix of assets. Formulae for basket options would typically have a static asset allocation, whereas the actual asset allocation will be subject to dynamic changes. The dynamic changes will not only be a function of market returns but also the financial health of the insurance company.

- Life insurance guarantees are often complex and include features typically found in exotic derivatives, such as smoothing, ratchets and barriers. Even without the issues raised in the previous bullet point above, it is not obvious that formulae exist for the complexity of some of these guarantees. Neither is it obvious that new products that will be developed will necessarily have closed form solutions. An insurer using closed form solutions for valuation may still find itself having to use Monte Carlo simulation on some products. This will create additional difficulties in maintaining consistency between valuations of different products.

- Many of the closed form formulae which are developed assume that log asset returns follow Geometric Brownian Motion (GBM). It is widely recognised in financial literature that this assumption is incorrect and that more complex stochastic processes are required to capture excess kurtosis and negative skewness in investment returns. More sophisticated models, including stochastic volatility or jump-diffusion, have been used to capture these effects. However, when these more sophisticated models are used, they are almost always used as stochastic models in any case, because it is not possible to derive a simple formula as with the Black-Scholes model.

- Fixed interest assets require special modelling to ensure they maintain arbitrage-free dynamics. Building in the arbitrage free dynamics of yield curve movements further complicates the development of closed form solutions.

Quantitative analysts have developed closed form solutions for exotic options traded by wholesale banks. However, evidence from quantitative analysts (Wilmott, 2001) suggests that Monte Carlo is still the most accurate calculation methodology for option pricing in situations where options are path-dependent and have high dimensions. 'Path dependent' means that the cash-flows derived from a contract depend on the way in which the underlying asset values move during the lifetime of the policy, not just what the asset value is achieved at the end of the contract. High dimensionality means that 
the cash-flows of the insurance contract are based on many underlying risk factors.. Participating contracts, such as with-profits, which depend on management actions and policyholder actions during the lifetime of the contract are examples of path-dependent options. Participating life insurance liabilities which have many types of asset in the asset portfolio are examples of high dimension options. Therefore typical participating life insurance liabilities are both path-dependent and have high-dimension, suggesting the Monte Carlo approach is likely to be the most efficient calculation method.

4.2.5. However, in some cases there is a compelling argument for using a closed form solution. For example, where the liability valuation has a low degree of materiality, the extra expense of doing a fully scenario based valuation could be rejected.

4.2.6. In the case of a small insurance company, the use of a closed form approximation could be justified on the grounds of proportionality. For example, the cost of introducing a fully stochastic valuation could result in a disproportionate cost relative to the size of the company. Furthermore, a small mutual insurer may have a very high solvency margin relative to the industry and could argue that policyholder protection would not be compromised by a closed-form solution approximation.

4.2.7. Considering a complex option which can be valued using a closed form solution, it is possible to estimate the price by estimating the implied volatilities and implied correlations for the Closed Form Solution. This is however difficult, as it is rarely obvious what the values for these parameters should be, unless there is a liquid market.

4.2.8. The alternative to the closed form solution is to use an ESG model, which is calibrated to certain instruments for which the implied volatility is known and to use economic theory (via the model structure and economic variable estimates) to supplement these values.

4.2.9. In practice, the observations have resulted in most reasonably sized insurers preferring to use an ESG model to calculate the market consistent value of their liabilities.

\section{3. $\quad$ Replicating Portfolios}

As a means of insurance liability, valuation replicating portfolios suffer from many of the same issues as closed form solutions. As a result, replicating portfolios are generally not used for primary valuation. For primary valuation, an ESG model is still preferred. The term primary valuation refers to the base case market consistent valuation using a full set of market consistent ESG scenarios. Replicating portfolios lend themselves to revaluation work, where it is desired to know approximately what the primary valuation would move to under revised economic scenarios Revaluation work typically requires fast computation of the revaluation.

\section{The Market VAlue Balance SHeEt}

\subsection{Introduction}

Market consistent valuation will be mandatory under Solvency II for all (re)insurance companies, for both assets and liabilities. For most EU countries and insurers, this will represent a dramatic change to the way in which their balance sheet is constructed. The last section focussed on why an ESG might be used for market 
consistent valuation. This section therefore focuses on market consistent valuation in more detail and considers what products can be valued using a market consistent valuation.

\subsection{Assets}

The market values of many assets are readily available from market data sources. Where more exotic (for example derivative) assets are held, the insurer may use data from the issuing bank or possibly a broker to decide what the valuation should be. Alternatively, the insurer may choose to use an ESG model to value the asset in a mark-to-model way.

\subsection{Liabilities}

5.3.1. This section considers some examples of the lines of business which lend themselves to Monte Carlo valuation using an ESG.

5.3.2. Considering the broad categories of Life, Non-Life and Health Insurance, the pre-dominant use of the ESG model approach to valuation is the Life Sector and therefore most focus is directed here.

\subsection{Asset-Liability Coherence}

5.4.1. It is quite possible that there will be a market consistency mismatch between the assets and liabilities. For example, derivative prices in the market can reflect many implied volatility surface shapes and bond prices can reflect many yield curve shapes. However, it is in the nature of many ESG models to have constraints around the shape of yield curves and volatility surfaces which can be accommodated. This can lead to identical cash-flows streams on the asset and liability sides of the balance sheet having different valuations.

5.4.2. The insurer will need to decide whether it is better to have exact coherence in valuation between the two sides of the balance sheet, or to accept that there will be an accurate asset valuation and an approximate liability valuation. Whatever decision is taken will need to be justified and the approximations documented.

5.4.3. In CP40, CEIOPS issued its proposal on the risk free rate (reference rate) to be used in the Solvency II implementing measures. CEIOPS proposed to use a risk-free interest rate term structure based on rates published by a designated third party, for example the European Central Bank in the case of the Euro risk-free term structure. This will cause an immediate mismatch in respect of derivative contracts which use the swap rate as the risk-free rate. This will expose insurers to an asset-liability mismatch risk by virtue of the basis risk between the swap rate and the government bond rate, even where the assets and liabilities are (apparently) cash-flow matched.

\subsection{Life Insurance - Traditional Participation Contracts}

5.5.1. Within the Life Sector, it is the traditional with profit style participation contracts with guarantees on a policyholder fund which frequently require an ESG model for market consistent valuation. This is by virtue of the large number of risk factors affecting the underlying fund and the complexity of the guarantees which are typically offered, as discussed earlier.

5.5.2. Considering U.K. experience, there is widespread use of ESG models in the valuation of U.K. style with-profits contracts where complex guarantees have been written on a fund of dynamically managed assets. Market consistent valuations are 
required to produce Market Consistent Embedded Values (MCEV), FSA Pillar 1 Peak 1 regulatory returns and the base position for the FSA Pillar 2 ICA.

5.5.3. ESG models are also used for the market consistent valuation of continental style interest rate guarantee products which can have complex guarantees. A classical continental endowment policy is a with-profit (participating) style contract which has some management discretion. The management discretion can adjust the participation rate (sometimes within the constraints of a legal agreement), the asset-allocation of the fund or recognition of investment earnings for the purpose of participation. The management and policyholder behaviour are dependent on each other and the prevailing economic conditions. This makes the modelling complex and challenging. Market consistent valuations of these products are required for Market Consistent Embedded Values (MCEV) and the Swiss Solvency Test (SST). These valuations are done using ESG models.

\subsection{Life Insurance - Unit-Linked Contracts}

5.6.1. Unit-linked lines have a large degree of market exposure by design. However, the cash-flows to policyholders have a more linear relationship to the market value than participating contracts. This makes market consistent valuation a relatively simple exercise which does not usually require the use of an ESG model.

5.6.2. Even where guarantees on unit linked contracts exist, or where charges and expenses cause non-linearity, they may be simple enough in structure that simple closed form solutions, (such as the well known Black-Scholes-Merton model) could be applied. However, if policyholder behaviour (e.g. lapsing, paying up) is dependent on economic conditions, the use of an ESG might be more appropriate. In this case, linkages between policyholder behaviour and economic conditions can be built into an insurer's asset liability model to capture the required dynamics.

5.6.3. Some contracts, though have more complex guarantees. A typical continental unit linked contract, for example, has a maturity benefit guarantee which is the bigger of the fund value and a rolled up value at maturity. The roll-up rate is usually guaranteed by the insurer and applied to the accumulated premia net of charges. In such cases, where future premia impact the guarantee, valuation using an ESG model is likely to improve the accuracy of the calculation in a material way.

\subsection{Life Insurance - Variable Annuities}

5.7.1. An emerging line of business (in Europe and therefore subject to Solvency II) which requires an ESG model for valuation is Variable Annuities (VA). Variable Annuities with benefits such as GMWB (Guaranteed Minimum Withdrawal Benefit) have complex embedded options on baskets of asset classes. These products lend themselves to Monte Carlo valuation. Contracts where the basket can also be amended dynamically by the policyholder lend themselves to Monte Carlo valuation even more strongly.

5.7.2. VA contracts have been more common in the USA and Far East than in Europe. Therefore valuation may not be material for many European-only entities at present. However, where European insurers are consolidating overseas entities with significant VA exposure, the market consistent valuation of these contracts may become material. Even so, the market consistent valuation of these contracts is an important consideration in the pricing and reserving of these products. 
5.7.3. Market consistent valuation of VA contracts is also important in the day to day management of a VA book of business. Many VA businesses dynamically hedge their VA liabilities to manage the asset liability risk. This typically requires a market consistent valuation recalculated using different sensitivity tests. The sensitivity tests usually change key underlying drivers of the VA valuation, such as the yield curve level, equity index level or equity implied volatility. The sensitivities can be used to determine the optimal hedge portfolio. These sensitivities are also called deltas. By taking two sensitivity measurements for each underlying risk driver, the convexity (or gamma) can also be measured..

\subsection{Life Insurance - Annuity Pensions}

5.8.1. Annuity pension business which includes RPI (Retail Price Inflation)/CPI (Consumer Price Inflation) caps and floors can also lend itself to valuation using an ESG. The case for using an ESG model for valuation is less compelling in economies with a well developed market in inflation hedging instruments. For example, annuity writers in the U.K. have been able to obtain quotes for RPI (Retail Price Inflation) and LPI (Limited Price Inflation) swap contracts. LPI contracts pay out the same cashflows as RPI contracts except that they have an upper cap of 5\% and a lower floor of $0 \%$ on the RPI inflation rate used for determining cash-flows. Because they are able to construct a replicating portfolio for the financial risk in their annuity liabilities using these swaps, an ESG model has not normally been required for valuation.

5.8.2. ESG models lend themselves to the market consistent valuation of Dutch-style conditional indexation pensions. Often the indexation of pensions is conditional on the solvency position of the Pension Company. The effect of this complex feedback loop on the valuation of liabilities can be measured using the ESG.

\subsection{Non-Life Insurance}

5.9.1. The life products listed above all have a significant element of market risks. For the most part, Non-Life insurance does not have a systematic risk component (i.e. correlated with market risk), with the potential exception of inflation exposure discussed in 5.9 .2 below. Where there is no systematic risk, valuation only requires the use of a risk free yield curve applied to the expected value of the best-estimate cash-flows.

5.9.2. There may, however, be a case for using an ESG model if there is non-linear exposure to inflation. Usually, the data used for projection of the loss triangles contains implicit historic inflation. A more market consistent approach could be to strip out historic inflation from the data and use information on inflation from the markets instead. Further research is needed however, to assess how material this is.

5.9.3. Another possible use of ESG models in non-life insurance might arise where claims (incidence and/or severity) are related to economic conditions in a non-linear way. A particular example is bodily injury claims linked to inflation that are reinsured in a non-proportional manner, where the indexation of the deductible is not at the same rate as the inflation behaviour of the larger claims.

\subsection{Counterparty Credit Risk}

5.10.1. Premium inflow from corporate partners or capital support from a parent or re-insurer can be a very large source of counterparty credit risk for which credit modelling should allow. Consider a block of in-force business between a reinsurer and a primary insurer. The premium inflows to the reinsurer have credit risk, depending on 
the credit standing of the primary insurer. Therefore, the different credit standings of primary insurers should lead to different values of the premium cash inflow to the reinsurer. Meanwhile, the outflows from the reinsurer to the primary insurer, being policyholder benefits, should be discounted at the risk-free rate.

5.10.2. The issue of counterparty default can thus be expressed in terms of interest rate term structures. One approach to market consistent valuation would be to strip cash-flows into cash-inflows and cash-outflows. By taking the view that cash-outflows are policyholder guarantees and that premium income is subject to credit risk, it could be argued that one should discount cash-outflows at the risk-free rate and the cashinflows at a higher rate, allowing for a spread in respect of counterparty credit default risk and the credit risk premium.

5.10.3. Another example of counterparty credit exposure is a large derivatives position. In this case, detailed modelling of the individual counterparty exposure would be more important. In this regard, it should be noted that typical collateralisation arrangements for these contracts, whilst reducing counterparty risk do not eliminate it. In conditions of market stress, such as those observed in 2008, it is possible that adverse market movements result in collateral calls which the counterparty is unable to provide. Where the counterparty exposures are well diversified, common factors affecting many counterparties would be more relevant to model.

5.10.4. Using an ESG model has the advantage that the counterparty credit exposure can be treated in the same stochastic scenarios as the other financial and credit risks. However ESG models to date have tended to have a broad brush approach to modelling and calibrating credit risk. A proper treatment of counterparty credit risk would require detailed modelling of the credit risk for the specific counterparty exposures. Nonetheless, if the link between credit and other underlying risk factors is a more significant than the credit risk in isolation, the broad brush approach is more useful.

\section{THE ROLE OF ESG MODELS IN SOLVENCY II INTERNAL MODELS}

\subsection{Introduction}

ESG models are not required to be used for Solvency II. However, this paper argues that many insurers will find of the requirements of Solvency II easier to meet using an ESG model. This section briefly discusses the use of ESG models in the standard formula, as this will be relevant to many firms. Next, the role which ESG models are likely to play within a Solvency II Internal Model is discussed. Firstly, the Full Internal Model is discussed in some detail. Finally the Partial Internal Model is discussed. In this section, references to an Economic Scenario Generator when discussing (partial) internal models are, unless otherwise stated, referring to real-world scenarios, as these are used for projecting the market consistent balance sheet and calculating the SCR.

\subsection{Solvency Capital Requirement (SCR) - Standard Model}

6.2.1. The standard model will not require the use of an ESG model per se, except that, in order to calculate the SCR, the market consistent balance sheet will need to be recalculated under each of the stresses described in the standard model.

6.2.2. Therefore, in addition to calculating the base market consistent value of assets and liabilities, insurers will also have to calculate the market consistent value after 
separate shocks to each of the equity, property, credit and fixed nominal interest rate markets (yield curve shifted up and yield curve shifted down). CP69 and CP70, issued in November 2009, also introduced equity and interest rate volatility shocks.

6.2.3. The application of these market stresses to the base balance sheet will require the valuation model to be re-run and in most cases the ESG model will need to be recalibrated, especially now that volatility stresses are included. For formal external reporting, the approach is likely to involve a full set of detailed calculations. However, for other purposes, such as the need for ongoing monitoring of the solvency position, less computationally intensive approaches are likely to be sought, which deliver results to within an acceptable level of accuracy, but faster and with reduced effort. One approach seeing increasingly widespread adoption is the use of replicating portfolios.

\subsection{Full Internal Model}

6.3.1. There are some compelling reasons why an insurer or its regulator would believe that a full internal model using an ESG model would improve the understanding of its risks and its risk mitigation strategies. These include:

- The ability to reflect the insurer's own views of the way economic variables might develop in the future and the statistical relationships between those economic variables. For the avoidance of doubt, this section is making reference to the realworld projection of economic variables, over which there could be much subjectivity, as opposed to a market consistent projection of economic variables over which one would expect more conformity.

- The calculation of 99.5\% Value-At-Risk (VaR) based on a more sophisticated one year stochastic projection can allow more credit to be taken for the mitigating impact of management actions as simulated economic conditions unfold during the year. This can have a material impact on the required economic capital.

- The ability to generate full distributions of capital, rather than just point estimates at given percentiles, gives a deeper understanding of the market risk. For example, consistent Economic Capital measurements can be made at various $\mathrm{VaR}$ percentiles or using Tail VaR approaches. In this way different risk measures can be tested from a single set of scenarios based on the same set of economic assumptions. The Level 1 Directive says that producing a full risk capital distribution is the preferred method, where this is feasible (for example, see Article 120 (2)).

- The use of combined market risk scenarios generated by the ESG model removes the need for external aggregation of these risks, e.g. via a correlation matrix or copula. Using an ESG model will also pick up the impact of any non-linear interactions between the modelled risks automatically. Having said this, the problem of modelling dependencies migrates to the ESG model, although the problem is then often more narrowly defined as modelling the dependency between economic variable, for which more data is generally available. This point is addressed in more detail in the section on dependencies below. 
- Using an ESG model will not remove the need for external aggregation using correlations or copulas where market and credit risk capital need to be aggregated with other risk capital, such as insurance or operational risk. However, some insurers intersperse risks considered to be independent of market risk (e.g. mortality and natural catastrophe risk) with the scenarios from an ESG. This creates a broader set of stochastic scenarios which can be used to investigate non-linear interactions between market and some non-market risks.

\subsection{Dependency Structures}

6.4.1. Earlier in this chapter dependency structures were discussed. Because it is the dependency modelling that drives the capital benefits of diversification benefit this area is further discussed now. Dependency modelling in the UK ICA has typically been done using a correlation matrix approach, along with occasional additional tests to account for non-linearity. For example the medium bang approach to account for the non-linear dependency between interest rates and longevity in annuity portfolios. This is the most common approach to modelling non-linear effects for UK life insurance modelling.

6.4.2. More sophisticated approaches to dependency modelling have been used (or perhaps abused) in the banking sector where copula modelling of default dependency has been used to price structured credit products. While such dependency modelling can capture features such as elevated tail correlation - that is the tendency for lots of markets to become more highly correlated in extreme market conditions - the techniques used rarely seem to be rooted in economic theory. Instead they appear to be used for their mathematical tractability, and in some cases their ease of calibration. While these are doubtless practical features to have, the disconnect between the form of the copula and the underlying economics potentially leads to arbitrary (and more stringent) capital requirements.. If the tails of distributions require a good deal of extreme event data to be calibrated, then the calibration of a copula to the extreme joint tail events requires even more extreme event data.

6.4.3. ESG models have tended to follow a different approach, often building up a dependency structure from economic theory to provide an economic rationale to the dependency between variables. More importantly stochastic modelling through ESG models can expose the balance sheet issues related to the interdependency of risks, which simpler approaches such as stress testing and aggregation cannot pick up. The idea here is that it is not just a scenario which leads to ruin but rather a path. This has been shown to be especially true in the recent financial crisis where the interaction of risks (for example credit and market) had, over time led to a very severe event occurring and threats to institutions previously considered safe.

6.4.4. ESG model providers seeking to offer combined market risk and credit risk scenarios need to consider how they link their market risk and credit risk scenarios so that positive feedback loops which strongly aggregate risks are captured. Several factors also impact on dependency and cause issues in the modelling.

\subsection{Internal Model Tests}

6.5.1. Article 110 (old numbering) states that to get the benefits of an internal model, a regulator needs to be comfortable that the company's risk management system can 
identify, measure, monitor, manage and report risks adequately. This is required to provide comfort that the model will at all times give sufficient protection to policyholders. It is also required to ensure that management have sufficient confidence in the model to pass the use test. As part of the process of getting this comfort, regulators will require seven tests to be passed before the model can be accepted into use. The tests are:

$$
\begin{array}{ll}
\text { - } & \text { Use Test; * } \\
\text { - } & \text { Validation Test; } \\
\text { - } & \text { Statistical Quality Test; * } \\
\text { - } & \text { Documentation Test; * } \\
\text { - } & \text { Profit \& Loss Attribution Test; } \\
\text { - } & \text { Calibration Test; * } \\
\text { - } & \text { External Data and Models. * }
\end{array}
$$

6.5.2. Below in sections 6.6 to 6.23.10, the paper considers how an ESG model would interact with a selection of the most important of these tests. The ones covered have an asterisk (*) next to them in the list above. In CP56, CEIOPS provides the proposed advice on treatment of internal models and details of what each of these tests.

\subsection{Use Test}

6.6.1. CP56 sets out some principles which underlie the Use Test. These include the Foundation Principle that there must be continual pressure to improve the model. If this principle is satisfied, then it provides strong evidence that the other principles are being met. In particular that two of the most important principle for our purpose are being met:

- Principle 1: Senior management, including the administrative or management body, shall be able to demonstrate understanding of the internal model.

- Principle 6: The internal model shall be used to support and verify decision-making in the undertaking.

6.6.2. To address the Foundation Principle, it would make sense to conduct an annual review of the ESG model as part of a wider internal model review process. This review could review any known weaknesses or new weaknesses which have emerged from using the ESG model during the year. Plans would then be developed to address any known weaknesses. Principles 1 and 6 are explored in more detail in this section.

6.6.3. Where an ESG model is employed as part of an internal model, it must be used to develop management information as part of the decision making framework for the insurance company, e.g. to inform the setting of the risk appetite and to inform the following areas:

- Financial reporting.

- Risk management.

- ALM management.

- Transactions (M\&A).

- Derivatives / Dynamic Hedging.

- Product pricing.

6.6.4. There is likely to be increasing regulatory interest in real-world ESG models used for calculating SCR requirements, as the economic assumptions and relationships within them impact on the way in which insurers view and assess market risk and thus start to influence major decisions within insurance companies. 
6.6.5. Sophisticated internal models might seek to lower market risk capital by demonstrating that management actions and timely hedging can mitigate risks. An obvious example is where a dynamic hedging strategy is used to mitigate risk of Variable Annuity guarantees. This will place a good deal more emphasis on the quality of the real world economic scenarios. In particular, their ability to project sufficiently extreme future paths - not just future scenarios.

6.6.6. If senior management and board members are to rely in the models, they must ensure that the company has a sound understanding of the features, strengths and weaknesses of the ESG model and that effective challenge has been provided to the methodology and parameterisation adopted. This should extend to understanding the key assumptions which are driving the results and the justification for those assumptions.

6.6.7. The insurer will need to demonstrate that the internal model feeds into the decision making around Risk \& Capital Management. It is therefore to be expected that major decisions will necessitate a full recalculation of the internal model which may require several recalibrations of the ESG. For example, the calculation of the SCR is likely to require several recalibrations of the market-consistent scenarios used for the valuation step. These recalibrations will need to reflect the different initial conditions required under each market stress.

6.6.8. The requirement to recalibrate the ESG more frequently could present major challenges if a recalibration cannot be performed easily and quickly. For example, the need to align an ESG model to an arbitrary set of economic assumptions and dependencies can be particularly challenging, as the distributions of economic variables and the dependencies between them in an ESG model are often strongly influenced by the model design.

6.6.9. In order to use the internal model (and therefore the ESG model) in major decisions, it is useful to have a common set of real world ESG scenarios used throughout the enterprise, against which all decisions would be based. This can put a lot of demand on the ESG model to capture many features of the various economies relevant to an insurance company in a single calibration.

6.6.10. If the ESG model cannot capture enough of the features of the economy, an insurer may find itself drawn into using different ESG models, or different calibrations in the different business areas. This would make comparisons of economic assumptions across the insurer more difficult and increases the risk of inconsistent decisions being taken throughout the business. Overheads are also increased if the ESG model (or calibration) in one business area needs to be reconciled to the ESG model (or calibration) used elsewhere.

6.6.11. In practice, there is likely to need to be a trade-off between choosing a model (and calibration) which can be used in many areas of the business and a model (and calibration) which can be easily communicated within the business and to senior management.

6.6.12. It is also useful to have a common set of scenarios for market consistent valuation, so that different parts of the business have a common view of the value of a piece of insurance business.

\subsection{Validation}

6.7.1. CP56 describes the validation test as a very wide ranging test covering the validation of not only the calculation kernel (or which the ESG model is a part) but 
also the systems and processes around the calculation kernel. The paper talks of insurers having a validation policy covering such items as validation purpose, frequency, tools, governance, limitations, future developments and independent review. As some of these topics are covered elsewhere in this paper, this section limits its scope to discussing the basic quantitative validation tests which need to be undertaken on ESG models to derive comfort that the ESG model works. The issues in conducting these tests are discussed.

6.7.2. The scenarios produced ESG models will need to be validated against the input. While market consistent ESG scenarios need to be validated against market data and target prices, the validation process for real world economic scenarios is perhaps more challenging and less well developed. Because the main concern is the SCR and because of the more significant challenges involved, this section focuses on the validation of real world scenarios.

6.7.3. Validation requires a demonstration that the output of the ESG model is consistent with calibration parameters: means, volatilities, correlations (or other dependency measure), and higher moments (distribution asymmetry and fat-tails).

6.7.4. Back-testing is a concept frequently discussed in the context of Solvency II model validation. The term has been borrowed from the back-testing of VaR internal models in Basel II. In that context, back-testing involves re-calibrating the VaR model to historic periods of time, often at daily intervals, and measuring how many times the actual losses exceed the VaR limit. In this way, the validity of the bank's internal model is tested.

6.7.5. The equivalent tests for an insurance internal model would be to re-run the full ALM system at past dates. The required solvency capital at each date could then be calculated. Using current ALM technology it is not practical to back-fill daily ALM results, even if an insurer had a daily history of policy, asset and expense data stretching back several years (which is unlikely to be the case). Even if it was possible to measure on a daily basis the issue of overlapping (non-independent) observations would still arise.

6.7.6. Considering an ESG model in isolation, one approach to back-testing would be to recalibrate the ESG model to dates in the past, perhaps annually, and to test how often the actual annual return exceeds the VaR percentile calculated using the ESG. This is a question frequently asked of ESG models in the aftermath of the 2008 crisis. The value in trying this validation is that it can test the calibration methodology and provide comfort (or not) about the algorithms used for calibrating the ESG. However, several problems arise in trying to do this back-test:

- For several elements of the calibration it may not be possible to have sufficient data going back in history. This makes recalibration to earlier dates challenging. Data such as long term equity implied volatility data may only be available for say a 10 year history, and then only for short option terms. This is more of an issue for market consistent ESG models used in the technical provision calculation because real world ESG model projections tend to be calibrated to statistical analysis of a long window of time series data. However, real world ESG models which use historic implied volatility time series to calibrate their models will also suffer difficulties calibrating to earlier times. 
- This can also be an issue for real-world ESG models which are usually calibrated to historic data. The risk measure of 1 Year 99.5\% VaR is typically of interest. This means that, even with 100 annual recalibrations back to the beginning of the 20th Century, it is a struggle to infer any conclusive statistical analysis from the result (Frankland et al., 2008). More frequent recalibrations could be made but the results would suffer from statistical bias due to the overlapping time periods. Nonetheless, some additional information is captured by taking this approach. An example is where a market crashes and then recovers before the year end. In such cases using an annual projection from each month end will better capture the market crash events that have occurred.

- From a practical perspective, many of the more complex ESG models which might be expected to pass this test (at the time of writing) have calibration procedures which involve manual intervention. Doing a Basel II style back-test would therefore be a major undertaking.

6.7.7. There is likely to be a trade-off between the validation test and the use test. The validation test requires the demonstration of a high degree of accuracy in calculations. However, this accuracy might be difficult to achieve in a timescale which would mean the firm could use the model for decision making, and thereby satisfy the use test.

6.7.8. A key aspect of validation using ESG models will be how many scenarios are used. For example, in measuring the VaR in the tail of a distribution, many scenarios are needed to improve the confidence interval around the $99.5 \%$ percentile capital estimate. This could lead to solutions where ESG scenarios are concentrated on a particular area of interest, for example the tail of a distribution. However, the complex nature of insurance business could reduce the effectiveness of such techniques. This is because extreme events for the solvency of an insurance company could be caused by non-extreme paths or events in the ESG. Also, understanding the behaviour of solvency under less extreme events is very useful for management understanding and decision making purposes and this insight would be lost if attention were just focussed on the distribution tails.

6.7.9. CP56 also discusses the need for sensitivity testing to explore the robustness of the ESG model. For example, if the results of the market consistent valuation are very sensitive to small changes in the calibration inputs then the models robustness should be investigated.

6.7.10. Another CP56 requirement is the reverse stress test. ESG models have a key role to play in these tests because of their ability to generate a significant number of different paths. It is instructive for the management to be able to consider the possible paths that lead to insolvency rather than just the combination of instantaneous stresses that lead to insolvency.

\subsection{Statistical Quality}

6.8.1. The CP56 section on statistical quality covers many areas of direct relevance to ESG models. Topics covered in the consultation paper include dependency and diversification, risk mitigation, probability distribution forecasts, actuarial and statistical techniques, data standards, risk ranking, financial guarantees and contractual 
options and future management actions. Discussion of many of these can be found elsewhere in the paper while others require a quantitative discussion beyond the scope of this paper. This section focuses on some of the issues relating to actuarial and statistical techniques, and data standards.

6.8.2. A major aspect of the statistical quality standards which will affect ESG models will be evidence that the economic data used to calibrate the model was of sufficiently good quality and relevant to the purpose of the ESG model calibration and the risk exposures of the insurer.

6.8.3. Considerations for this test could include the treatment of outlier observations in the calibration data. If these are omitted from the data set then justification will be needed to explain why this was done. If the data point cannot be discounted then the model's ability to represent such observations will need to be considered. If the model has limitations on reproducing extreme events, it might be appropriate to employ a more sophisticated model which better represents the data. For example, by capturing skew (distribution asymmetry) or excess kurtosis (fat-tails).

6.8.4. For some asset classes such as Private Equity, Hedge Funds, or Real Estate, data is limited and can contain bias and/or significant sampling error. It is to be expected that these limitations will need to be recorded under the Solvency II 'Statistical Quality Test', and that simplifications or judgements made about the data will need to be explained clearly. Where assets such as real estate are valued using expert judgement, the prices should be checked against actual transaction prices whenever possible. CP56 places significant emphasis on the justification of expert judgment.

6.8.5. Another aspect of the statistical quality standards which is worth discussing in the context of ESG models is the requirement to ensure that data used is accurate, complete and appropriate. Ensuring the accuracy of data will be very challenging. It is to be hoped that 'accurate' is interpreted as being accurate on a best efforts basis. Whether a data set is appropriate is open to debate, but evidence of the thought process and decision taking will be important in this regard. Below in sections 6.8.6 to 6.8.8, the complete requirement is considered in more depth. The context of market consistent valuation is used as an illustrative example.

6.8.6. In the market consistent valuation of an ESG model, subsets of market consistent data are used for the calibration where available. For example, a model may only calibrate to at-the-money option data. This is typically the case where a simple model is being used which cannot be calibrated to a larger subset of data. Where this occurs, it will have to be considered whether the increase in model complexity which is required in order to make use of the full data set is justified. If using complete data would make a material difference compared to a sub-set, then the argument for using a more complex model would be stronger.

6.8.7. Arguments against using a more complex model to meet the complete requirement could include failure to comply with the Use Test, because some of the complex model results cannot be understood sufficiently and therefore management do not feel comfortable using the model for decision making.

6.8.8. In practice, a trade off will be necessary and the case for the choice made will need to be documented. It remains to be seen how supervisors will react to this sort of trade off. 


\subsection{External Models}

6.9.1. As ESG models are frequently provided to insurers by external providers, the provisions within the Solvency II Directive about external models will often apply to the ESG. Requirements where an external provider is used, would at first sight appear to be less onerous, given that Solvency II is aiming to align with Basel II rules on external providers. However, CP56 is also clear that insurers will need to offer and document effective challenge to external providers including benchmarking external models against their own models and explaining their exit strategy from dependence on the external supplier. Furthermore, all tests for an internal model will equally apply to an externally sourced component of the internal model. It is therefore clear that insurers have a good understanding of their external model.

6.9.2. In CP56, CEIOPS sets out what would be considered necessary to show that an insurer had a good understanding of its external model:

- In-depth knowledge of the methodological underpinnings and basic construction of external models and data, including an understanding of the models' capabilities, limitations, and appropriateness for use in deriving the SCR.

- Demonstration of a full understanding of the effect and significance of the proprietary elements in the external models.

- Documentation of the rationale behind any judgment-based overrides or any other adjustments made to external data sets or external model outputs.

- Retention of in-house expertise on the External models and data for as long as these are used to derive the SCR.

6.9.3. Potentially the most onerous requirement is the amount of documentation around decision making, which can often take place to tight timescales in order to meet year end reporting deadlines. One approach could be to pre-agree a process which will be followed for making judgements. Then only judgements which deviate from the pre-agreed policy will need to be recorded.

6.9.4. It appears likely that commercial ESG model providers will need to provide a significant amount of information to insurers about the model choices which they have made and what the weaknesses of the chosen models are. Understanding the documentation requirements for an internal ESG model will be a valuable toolkit for insurers to ensure that external providers meet the same criteria that the insurer would have to provide. A description of the types of documentation required for an ESG model are set out in the Documentation section below starting in section 6.10.

\subsection{Documentation}

6.10.1. In this section, the key areas of ESG model documentation are set out and described. The areas covered are:

- Methodology.

- Methodology - Mathematical Basis.

- Methodology - Empirical Basis.

- Methodology - Assumptions.

- Methodology - Application of Expert Judgment.

- Methodology - Where it doesn’t work.

- Formulas and Parameters. 
- Formulas and Parameters - Method for Estimating Parameters.

- Formulas and Parameters - Data Policy.

- Formulas and Parameters - Source Code.

- Future Developments.

- IT Integration.

6.10.2. In CP56, CEIOPS describe the need for different levels of documentation within an organisation. Most encounters with an ESG model within an insurance company will be through the documentation and therefore discussion on the levels of documentation, particularly for senior management, is covered in the Governance section in the next section.

\subsection{Documentation - Methodology}

The documentation of the methodology describes the thought processes which have taken place to arrive at the ESG model which the insurance company is using. The methodology documentation should also demonstrate the insurers' understanding of where the model does and does not work.

\subsection{Documentation - Methodology - Mathematical Basis}

6.12.1. The mathematical basis for an ESG model would describe the underlying mathematics which has been used in the model. The main mathematical concept used for the market consistent valuation is risk-neutral valuation and the use of martingales. Best practice documentation would show mathematically that the average of the discounted cash-flows from any asset (or combination of assets) would equal the starting value of the asset (or combination of assets).

\subsection{Documentation - Methodology - Empirical Basis}

6.13.1. For an ESG model, this would be the empirical justification of a particular model being used. A common example would be a comparison of the empirical distribution of asset returns with the distribution assumed in the ESG model. This is not to say it will always be desirable to get the best fitting distribution to a market risk as, there are other factors to consider such as materiality, ease of integration with other risks and ease of communication which will need to be considered.

\subsection{Documentation - Methodology - Assumptions}

6.14.1. Assumptions or prior beliefs are endemic in the building of ESG models, because the data at our disposal will rarely if ever provide enough certainty regarding model choice and parameter estimation. By way of an example, consider equity interest rate correlation. Assumptions used in an ESG might include that:

- Correlations derived from historical data are sufficiently free of sampling error to be used without adjustment.

- Correlations measured over the past 10 years are an unbiased estimate of the correlations over the next 1-40 years.

- The average composition of the FTSE-100 and the exposure of its constituents to, say, 10 year government bond rates, over the last 10 years will remain the same for the next 40 years.

\subsection{Documentation - Methodology - Application of Expert Judgement}

6.15.1. CP56 describes the need to document expert judgment. For an ESG model, this is related to the assumptions which have been made during the design and 
calibration of the ESG model. Assumptions include subjective choices over models which are chosen, algorithms which are used and data which are used for setting parameters. However, expert judgment extends this to require documentation of the process which is followed in deciding the assumptions and calls for documentation of the qualifications of the person making that judgment.

\subsection{Documentation - Methodology - Where it doesn't work}

6.16.1. This is a very important document which will provide senior management with the circumstances, or blind spots of the models they use. By documenting where a model does not work insurers are able to record economic circumstances in which his ESG model will fail and give misleading results. Best practice would be to maintain several models or model combinations, which would cover each others' blind spots and document a change process in the event that a different model was required. This would mitigate the reputational risk of needing to change model mid-crisis because a previously sensible model has stopped providing reliable answers.

6.16.2. This is perhaps the hardest documentation for a ESG model designer to write. The model designer may not realize some of the model weaknesses, because they have been too close to the design and build. Widely published academic models can become valuable in these circumstances. Academic models are published and when presented at academic conferences are subject to critiques by an equally well qualified peer group. This helps insurers by providing a ready made source of critiques explaining where the academic model does not work.

\subsection{Documentation - Formulas and Parameters}

Documentation of the formulae and parameters is an obvious documentation requirement. This would include all formulae and parameters, including those used in the calibration engine of the ESG model, as well as the projection engine of the ESG model. Different ESG model calibration algorithms can lead to different ESG model parameterisations, given the same input data. Therefore documenting the whole of the ESG model is important.

\subsection{Documentation - Formulas and Parameters - Method for Estimating Parameters}

ESG model calibration procedures are typically a mixture of expert judgment, statistical analysis and market data. Documentation will need to cover the statistical methods used and where market data has come from. In some cases, market data will be available from public sources. A potential issue arises where subscription data sources have used proprietary methods to infer data points. Insurers and their regulators will need to be comfortable with how external proprietary data methods would perform during a financial crisis, or include a process to circumvent their use. Some market data on over-the-counter derivative instruments used in ESG model calibration are only available privately and this will need to be documented.

\subsection{Documentation - Formulas and Parameters - Data Policy}

Data will be an important element of the estimation of parameters for an ESG model. Therefore, in order to ensure that senior management can have confidence in the assumptions used, an insurer will need to have a data policy in place. The data policy will also help to communicate the insurer's approach to the use of data. 


\subsection{Documentation - Formulas and Parameters - Source Code}

The documentation of source code would be straightforward for an internal ESG model, although an external commercial ESG model provider would probably only permit access to source code under an escrow agreement. An escrow agreement would allow access to the code should the owner of the source code become insolvent.

\subsection{Documentation - Future Developments}

CP56 discusses the need to document proposed future changes to the internal model and it could be imagined that this would include the ESG. For an external provider, the insurer will need to get clear documentation of the development pipeline, delivery schedule and numerical impact of model changes in order to document future model changes or to decide whether a proposed model update is used and if it constitutes a major model change. If it does, it will need to be approved and information about the approval of the change will need to be disclosed. Furthermore, documentation will need to be provided showing the insurance company's latest solvency position under the original model and after the changes have taken place.

\subsection{Documentation - IT Integration}

The documentation of the IT integration will affect the ESG model, as it is typically delivered as a software system and integrates with Asset Liability Management software. Documentation could include a description of the IT platform in which the ESG model is deployed and back up plans in case of IT systems failure.

\subsection{Calibration}

6.23.1. In CP56, CEIOPS discuss the requirements for using a different risk measure to evaluate the Solvency Capital Requirement (SCR). The baseline risk measure is the 1 Year 99.5\% VaR of the Basic Own Funds. In order to permit deviation away from the baseline risk measure, CEIOPS require equivalent protection for the policyholder. This is achieved through requirements such as: justification of different time horizons; tests for intermediate solvency; benchmark portfolios; and recalibration of the risk measure to the baseline risk measure at least annually. This section discusses some of the reasons why a different risk measure might be considered and how ESG models can help to translate from one risk measure to another.

6.23.2. VaR has been criticised as a risk measure; notably for not being a coherent risk measure and ignoring the severity of losses beyond the particular percentile (Artzner et al., 1999). Alternatives which have been proposed include Tail Value-atRisk (TVaR), which addresses the limitations of VaR described above. Nevertheless, $\mathrm{VaR}$ has practical advantages with regard to its relative ease and speed of calculation, broad application and is widely perceived as easier to communicate.

6.23.3. For many lines of insurance business, particularly in the long term saving market, longer term risk measures are more aligned with the strategic management of the business. An insurer may wish to use a long term measure, for example to have enough capital over 40 years to a certain percentile level. Under Solvency II, the insurer will however, need to demonstrate equivalence of their long-term measure to the baseline risk measure.

6.23.4. There is no definitive way of proving this equivalence. To do so would involve proving that the amount of capital held using the insurer's measure offered 
equivalent policyholder protection to the baseline risk measure. The only way to achieve this would be to reverse engineer the calibration percentile of the insurer's risk measure that would always give exactly the same capital. This makes it questionable whether using a different risk measure adds extra insight.

6.23.5. However, an alternative risk measure could be used as long as it reconciled to the standard risk measure. According to CP56 supervisors will require recalibration of an insurer's risk measure percentile to the baseline risk measure at least annually and on any significant event or change in risk profile. This permits insurers to use their own risk measure with the reverse engineered percentile in interim periods. The reconciliation would then involve converting a one year horizon return distribution (the standard risk measure) into, for example, a forty year horizon return distribution (the insurers' risk measure).

6.23.6. ESG models offer a relatively easy way to create consistent return distributions for different time horizons which are all based on the same underlying economics and calibration parameters.

6.23.7. For example, say a particular percentile value (VaR) of an economic variable is known. An example might be the 99.5\% 1 year return of the CPI Inflation Index. This information is not enough to calculate other percentile values. In order to do this, the distribution of the CPI Inflation Index one year from now must be known. This could be achieved using a directly fitted parametric distribution, an empirical distribution or using a more complex distribution generated by an ESG model.

6.23.8. Knowing the distribution of an economic variable at a single time horizon is not sufficient to understand how the distribution evolves at different time horizons. For example, mean reversion, heteroskedastic (stochastic volatility) behaviour or complex inter-asset dependencies will influence the future distribution.

6.23.9. ESG models provide the full distribution and evolution of economic variables. Therefore they are straightforward to use for calculating economically consistent (if not necessarily equivalent) risk measures. However, there are some points to be aware of:

- The risk measures typically need to be derived empirically from the ESG model, which introduces sampling error. The sampling error is particularly strong in the extreme tails of the distribution which is of particular concern.

- Any ESG model distribution will depend on the model choices within the ESG model and its calibration. Subject to sampling error, the risk measures will all be coherent to the ESG model configuration and calibration used. If the ESG model and its calibration are only calibrated to a specific time horizon, then poorly calibrated risk measures may result if a different time horizon is used for the risks measure from the same ESG scenarios.

6.23.10. A well designed and well calibrated ESG model provides a sound approach to aggregating a short-term distribution of economic variables to a longer-term distribution of those same economic variables. 


\subsection{Partial Internal Model}

6.24.1. At the time of writing, CP65 on Partial Internal Models had not been published. Therefore this section is not able to provide a lot of detail on the specifics of that paper.

6.24.2. It is reasonable to expect that most partial internal model implementations will replace elements of the standard formula which were unsuitable for the type of business which the insurer had written. This could occur at the insurer's request, where the standard formula was considered to be inappropriate. Alternatively, it could occur at the regulator's request where the standard formula was not considered sufficiently accurate to capture the risks of the business. It could also occur where an insurer only had parts of their internal model approved.

6.24.3. It is to be expected that the market risk module is most likely to be replaced with an ESG model oriented partial internal model, where an insurer has a significant market exposure or a sophisticated asset strategy for which the standard model does not give credit.

6.24.4. Other uses for an ESG model could be to replace the default (counterparty credit exposure) module and provide a more realistic dynamic link between counterparty risk and the market risk module. Where such a partial internal model is used, the insurer will have to be satisfied that the credit model of the ESG model is appropriately calibrated. For example, a model calibrated to reflect the dynamics of a diversified portfolio of credit risky assets might not be appropriate to evaluate reinsurance counterparty credit exposures.

6.24.5. Assuming it is appropriate to model market and counterparty default together, there is an issue in that these are separate sub-modules of the standard formula. Therefore the standard formula correlations will not be suitable and different correlation assumptions will be required to aggregate the Partial Internal Model into the rest of the standard formula.

\section{THE ROLE OF ESG MODELS IN SOLVENCY II PILlARS 2 \& 3}

\subsection{Introduction}

7.1.1. CEIOPS paper CP33 describes the governance structure which Solvency II requires. The paper describes five areas of governance: Risk Management System; Internal Control; Internal Audit; Actuarial Function; and Outsourcing. Of these, the risk management system, actuarial function and outsourcing are the most relevant to ESG models.

7.1.2. The risk management system is described as covering: underwriting and reserving; asset-liability management; investments; liquidity; concentration; operational risk; and risk mitigation techniques. There are quite a few detailed areas covered by the risk management system, where ESG models will be important. The obvious areas are: asset-liability management; investments; and risk mitigation, although all areas could be written about. CP33 also describes the role of the risk management function as the owner of the internal model. For an ESG model, this means that the ESG model used in the internal model could be owned by the risk function, especially the real world ESG and assumptions which it uses for calculating the SCR. 
7.1.3. CP33 also describes the actuarial function as being the primary function responsible for the calculation of technical provisions. From an ESG perspective, this suggests that the actuarial function would be responsible for the market consistent valuation use of the ESG model. Splitting the ownership of the ESG model between two functions dependent on which calibration or subset of models is used, seems like unnecessary duplication. In the U.K. and throughout Europe, many insurers are still working through what the split between the risk function and the actuarial function will mean in terms of roles and responsibilities.

7.1.4. CP33 also describes the governance around outsourcing. This will be relevant where an ESG model has been outsourced to a third party provider. The paper makes it clear that outsourcing any important or critical activity (such as the setting of economic assumptions) does not exonerate the insurers' responsibilities. Indeed, the insurer will need to get a good deal of contractual assurance from the $3^{\text {rd }}$ party provider, including evidence of the internal control and governance structures in place at the $3^{\text {rd }}$ party provider.

7.1.5. There has been much written and presented on general governance structures within insurance companies and many good papers have been written on this subject recently. For example, Deighton et al., (2009) which discusses Governance in an ERM framework and Morgan et al., (2009) which addresses governance in the context of internal models for Solvency II. It is not the intention of this paper to join that wider debate.

7.1.6. From an ESG modeller perspective, governance of economic assumption and economic models looks somewhat different to that set out in CP33. The intention of this section is therefore to focus on some key functions involved in the governance of an ESG model and to share thoughts on where different responsibilities should lie and what each function might need to produce or receive as part of its duties. Finally, this section tries to infer how these ideal ESG governance roles interlink with those roles described above in CP33. It should be pointed out that the governance structure of different insurers varies and in practice it will be necessary to tailor a governance structure to the individual company. This is because the target structure will need to evolve from the existing governance structure as well as incorporate the governance structures required by Solvency II.

\subsection{Key ESG Model Related Functions}

7.2.1. The governance of ESG models poses particular issues for Insurance Companies because their design can be mathematically complex and yet the skills to understand this mathematics are not to be widely found within Insurance Companies. Indeed, while the ESG models typically used in Insurance companies are often borrowed from banking models, knowledge of their implementation and how they are combined together is not widespread. Where those skills do exist in insurance companies, they are often found in more junior roles.

7.2.2. However, for many companies, especially Life Companies exposed to market risk, the model choices and calibration choices can be key drivers of the financial results. Therefore, senior management need to understand how to set up an effective governance framework for their ESG model.

7.2.3. Key ESG-related governance functions are described in section 7.3 onwards. This is not intended to be an exhaustive list of the ESG model related functions, but 
hopefully provides a useful first step in understanding how senior management can engage with an ESG model.

7.2.4. With the exception of the day to day users of the ESG model, most interaction with the ESG model will come in the form of documentation. CEIOPS discuss the need for different levels of documentation for different purposes in CP56. Therefore, this section also suggests documentation which could be required for the different functions to discharge their duties.

7.2.5. The governance functions described are deliberately broad and often encompass two or more actual roles within the broader governance role. For example, the CRO and Chief Actuary roles are combined below into a Risk \& Actuarial Function. This reflects that in some cases these roles are combined and where they are split, the division of responsibilities can be very different depending on the company, especially when one considers insurers outside of the U.K.

7.2.6. This chapter distinguishes between producer functions and consumer functions. A producer function has a responsibility for the manufacture of ESG model related deliverables. These could include: a file of scenarios; an ESG report; or some input to the ESG model. A consumer function uses ESG deliverables to but do not produce ESG deliverables themselves.

\subsection{Producer Functions}

The three producer functions; the Risk \& Actuarial Function, the Economist Function and the Technology Function are discussed first.

\section{4. $\quad$ Producer Function - Risk \& Actuarial Function (Chief Risk Officer, Chief Actuary, Head of ALM)}

7.4.1. First, we describe the centralised framework. In this framework, the Risk Function typically owns the ESG model and has developed the expertise in using it. There are some good reasons for the ESG model sitting in this function, as the knowledge of quantitative stochastic mathematics used in ESG models typically resides here. The Risk Function also has a vested interest in the ESG model, as the quantification of market and credit risk resides in this area.

7.4.2. Typically, the Risk Function will historically have been responsible for the choice of models (perhaps building their own model), the calibration of the model (including the choice of economic assumptions), the operation and documentation of the model.

7.4.3. Looking forward, the owner of the ESG model will also be the owner of the Internal Model, which means that the Risk Function will continue to operate the model. However, the extra requirements to provide documentation around the working of the model, the calibration, the operation, expert judgement and changes to the internal model (including the ESG), will mean that this function needs to have a comprehensive documentation system around the ESG model if it does not already have one.

7.4.4. An alternative federal model involves the Risk Function setting guidelines and policy around the use of the ESG model and requiring business units to operate the model themselves.

7.4.5. As the primary owner of the ESG model, the Risk Function would have responsibility for producing different levels of documentation for effective governance of the ESG model around the firm. This could include reports for various consumer functions around the business. For example: 
- Board of Directors/Executive Board may want to see a report on the key market and credit risk indicators. Additionally, they may want to see the key assumptions which influence these key risk indicators and the rationale for choosing them.

- Finance Function may want to see a list of the key assumptions or data inputs to the ESG model, how these have changed over since the last reporting period and the rationale for them changing.

- Sales \& Marketing Function may want to see a report in which products are currently profitable or not profitable both now, and over the next business planning period. This will help to focus effort on acquiring profitable business or limiting sales on loss leading business.

7.4.6. The Risk Function would also have a responsibility to work closely with the Economist Function in setting the calibration assumptions, as the target assumptions may not be feasible in the ESG model and therefore a trade-off between reflecting the targets and the calibrating the ESG model will be required.

7.4.7. Where the responsibilities above are in relation to Technical Provisions, CP33 suggests that responsibility lies with the Actuarial Function. Where the responsibilities above are in relation to the calculation of Risk Capital, CP33 suggests that responsibility lies with the Risk Function.

\subsection{Producer Function - Economist Function (Chief Economist / Chief Investment Officer)}

7.5.1. The Economist Function is a new concept for Solvency II. However, the function of setting economic assumptions already exists in asset management, actuarial, risk management, board level or is outsourced to an external ESG Model/Economic Modelling provider. This paper argues that it is useful for the governance of ESG models to identify this function as distinct and to give careful consideration as to who performs this function and how it is performed. A benefit of an Economist Function is that they can ensure consistency of the assumption sets across the organisation.

7.5.2. The Economist Function owns the economic assumptions of the model, and as such owns the ESG model calibration assumptions. The Economist Function should be recommending the economic assumptions based on a methodology which they own. This either means developing their own econometric model or using an external provider where they have carefully reviewed the economic assumptions and taken ownership of them. It is then up to the senior management of the firm to set the economic assumptions. It is important for the business to own the economic assumptions, because for many insurance businesses, the economic assumptions are a key element of company strategy.

7.5.3. However, the economic assumptions the company chooses will not necessarily be feasible in the ESG models of the Risk \& Actuarial Function and a best fit will be required. As the owner of the economic assumptions, the Economist Function would need to see the quality of the fit and understand where the fit was good or not in order to the sign-off the calibration and produce documentation explaining the application of their expert judgment. It may be that the ESG model could be used to guide some of those prices. For example equilibrium models can help inform what size risk premia should be, in the light of an assumed co-dependency between asset price returns. 
7.5.4. ESG models are often quite passive models. This means that they are supplied with the distribution of future economic outcomes and then just project this. Therefore, other models (which might be econometric models) are required to derive proprietary economic assumptions. The Exposure Draft of the Modelling Standard issued by the Board for Actuarial Standards (BAS, 2009) describes any process for coming to a decision as a model, even if that model is just a thought process. Therefore, when reference is made to a model for coming up with economic assumption, the word model is used in a broad sense. The model could just be the thought process of someone in the Economist Function.

7.5.5. Economic assumptions are used throughout an insurance business. Obvious examples are in the calculation of Technical Provisions and Solvency Capital Requirement. However, to pass the use test it is very instructive if the senior management are to demonstrate a belief in the economic assumptions used for solvency in other areas of the business. For example, if the economic assumptions were believed, the Sales and Distribution Functions could demonstrate that they were being used for planning the product mix and distribution infrastructure of the insurer.

7.5.6. It would make sense for economic assumptions to be consistent across the whole insurance company. Indeed, it could be difficult to explain why decisions were being taken using conflicting economic assumptions across the business. This suggests a requirement for the centralised setting of key economic assumptions, along with the rationale for these choices. These assumptions would then be filtered out to all consumers of the economic assumptions within the business. In this way, there would be implicit pressure from many parts of the business for an improvement to the economic assumption setting. This would meet the foundation principle of the use test.

7.5.7. If the Economist Function recommends the assumptions, it would also need to adopt responsibility for demonstrating and documenting the appropriateness of expert judgement in coming up with the economic assumptions. This would be a key area in addressing the documentation requirement for the approval of an internal model. If the actual assumptions used were altered by the senior management, the Economist Function would be responsible for making the senior management aware of the supporting documentation required and assist with documenting the choices made.

7.5.8. The element of the Economist Function concerned with setting best estimate economic assumptions in the calculation of the Technical Provisions would sit naturally in the Actuarial Function described by CP33. However, the Risk Function, as owner of the Internal Model, or the Asset Management Function, as the function that makes economic forecasting judgement calls, could make a claim to own some element of the economic assumptions.

\subsection{Producer Function - Technology Function (Chief Technology Officer, Head of IT)}

7.6.1. The Technology Function would own the platform on which the ESG model sits and maintain the platforms and systems needed to run the ESG model and produce ESG model outputs.

7.6.2. The Technology Function would be interested in ensuring that the IT infrastructure around the ESG model was robust and that back up plans were in place. They would typically also monitor licensing of external IT vendors and may get involved in the procurement ESG software to ensure that it meets the criteria for deployment within the organisation. 
7.6.3. It would make sense for the Technology Function to produce documentation setting out the way in which the ESG model is deployed within the firm and how backup systems have been organised.

7.6.4. This function forms part of the risk management system, though not the risk management function. In overseeing the risk management system, the risk management function would be relying on the services of the Technology Function. It is difficult to envisage how the governance, internal model, documentation and reporting requirements of large insurers will be able to operate without a good deal of involvement from the Technology Function.

\subsection{Consumer Functions}

In this section, the roles of the key consumers of ESG model related deliverables are discussed.

\subsection{Consumer Functions - Finance Function (CFO)}

7.8.1. The Finance Function is not mentioned in CP33 but will, of course, be an integral part of the governance structure of an insurer in practice and is therefore its role in ESG governance is described here.

7.8.2. The Finance Function is typically a consumer of the output of ESG models and is typically being required to sign off or check calculations which impact on the financial statements. The Finance Function may also take the lead on Pillar 3 disclosures under Solvency II.

7.8.3. Where the Finance Function reports MCEV or EEV, the key assumptions and evidence for why they are correct will be important to disclose and explain to the Finance Function.

7.8.4. The documentation provided to the Finance Function would be likely to include the key calibration data driving the Technical Provisions and Solvency Capital Requirement, along with evidence of the source of the data to give the Finance Function comfort that the inputs were robust.

7.8.5. It will also be important for the changes from the last reporting period to be presented and the rationale for these changes. This can present challenges when using an ESG model, as many of the properties of ESG models are interconnected. For example, a change to interest rate volatility could have unintended side effects such as changing the correlations of interest rates to equity. Furthermore, the results of an ESG valuation will typically be subject to a reasonable amount of sampling error. Explaining all the movements can be a challenging. Typically, the more sophisticated models are at capturing market dynamics the more calibration side-effects are likely to be found.

7.8.6. Further reporting could include sensitivities of the Technical Provision and SCR calculations to the key calibration inputs to give the Finance Function further insight to the robustness of ESG model valuation. Where a valuation is found to be particularly sensitive to a calibration input, greater focus will need to be applied to the estimation of that input.

7.8.7. It could be expected that as many more firms around Europe move to market consistent valuation under Solvency II, and should IFRS-4 converge on to a market consistent valuation, the Finance Function would begin to become more engaged with the ESG model and may request more input to the Economist Function around assumption setting. 


\subsection{Consumer Functions - Sales and Marketing Function (Head of Sales / Head of} Product Design)

7.9.1. The Sales and Marketing Function is not mentioned in CP33. However, this is one of the most important functions for the governance structure because it is the place where value and risk are manufactured for the insurance company.

7.9.2. Many of the early ESG models were in fact provided to product designer (part of the Sales and Marketing Function according to this paper's definition). For a product designer, an ESG model needs to be an accurate reflection of the economic markets on which the insurance product is based. To capture the detailed nuances of market dynamics typically means using an ESG model, which would be more sophisticated than the models used for valuation of Technical Provisions.

7.9.3. As discussed earlier in this paper it makes sense to use the same model and assumptions around the insurer to ensure that there is consistency in the economic assumptions. However, in the area of product design, an ESG model which is good enough for the Risk \& Actuarial Function to calculate Technical Provisions, or calculate the SCR may be inadequate for product design. This is because the objective of the Risk \& Actuarial Function is to get broadly the right number when aggregating over many asset classes and markets, whereas the product designer is often more narrowly focussed on a particular market segment, where mispricing could cause a loss.

7.9.4. For example, when Variable Annuity products and their hedging strategies are being designed an ESG model better able to capture market dynamics will lead to more robust hedging and more profits.

7.9.5. A practical governance solution to the two models problem is to ensure that any new product is road-tested with the ESG model and calibration of the Risk \& Actuarial Function, as well as that of the Sales \& Marketing Function. This would ensure that the product was creating sufficient value to justify its capital requirement on the economic basis of the wider insurer. Furthermore, calculation of the difference in pricing and risk capital using two models can be an instructive way to understand model risk.

7.9.6. An ESG model report from the Risk \& Actuarial Function to the Sales and Marketing Function could include an update to the key movements in markets and the parameters being used for Technical Provisions and SCR. The Sales \& Marketing Function could also produce documentation setting out the cost and return on capital of manufacturing new or existing products. They could do this on the economic capital basis used by the Risk \& Actuarial Function and the basis of the Sales \& Marketing Function. This would be reported back to the Risk \& Actuarial Function and the Board of Directors so that the products or the product mix could be evaluated against the risk appetite of the insurer.

7.9.7. Another way in which an ESG model could be used by the Sales and Marketing Function is in the communication of risks and rewards of products to consumers. In the UK, as elsewhere in Europe, predefined scenarios are often used for product illustrations. While these have the advantage of being simple to explain they can mask the details of how products perform in a wide range of circumstances, particularly in the tails of distributions. ESG models have been used to illustrate the distribution of possible outcomes for various products, although these illustrations are usually provided to financial advisors rather than directly to consumers. 
7.9.8. The Sales and Marketing Function could issue documentation on the risk vs. reward of existing products to the Board of Directors. These could then be used to take a view on any products which were offering customers a poor return and which could lead to increased policyholder lapses or create issues for the insurer around conduct of business regulation. Where a poor return was being offered to certain customers, the insurer could take pre-emptive action to communicate with the customer, improve the deal and reduce lapse experience.

\subsection{Consumer Functions - Board of Directors / Executive Board}

7.10.1. The Board of Directors are mentioned at various points of CP33 and have been referred to throughout this section. The interaction of the Board of Directors will need to be high level. However, they will be seeking documented assurance that the ESG model is performing as it should and being used appropriately. This could include assurance that:

- $\quad$ the model design is adequate for the purposes for which it is being used;

- the implementation of the model is correct.

- the economic assumptions are valid;

- the changes of the economic assumption from the previous reporting period can be explained; and.

- $\quad$ the sensitivity of KPI (key performance indicators) and KRI (key risk indicators) to ESG model assumptions.

7.10.2. Where a company assumes significant levels of market risk in order to create value for shareholders, it could be anticipated that the Board of Directors' knowledge level and interest in ESG models and the economic assumptions used to calibrate them will increase over time.

\subsection{Pillar 3 - Disclosure}

7.11.1. At the time of writing, the disclosure requirements around Solvency II were still emerging. CP58 was released in the summer, but further details of the quantitative information required will be issued as Level 3 guidance. An extract from Article 50 of the Solvency II Directive discusses some disclosures which could be considered relevant to ESG models. The extract suggests that the (market consistent) valuation basis will need to be disclosed;

“... a description, separately for assets, technical provisions, and other liabilities, of the bases and methods used for their valuation, together with an explanation of any major differences in the bases and methods used for their valuation in financial statements;"

7.11.2. Where an ESG model is used for the market consistent valuation, a full description of the economic basis could be provided by supplying the full set of economic scenarios. While comprehensive, this would not be practical or help understanding. A solution developed by the U.K.'s FSA for the Pillar 1 Peak 2 Realistic Balance Sheet is to request that some pre-defined financial instruments are valued using the same economic scenarios which the insurer has used in its regulatory submissions. An adaptation of this option table approach could be a practical way in which the economic basis on an ESG valuation could be disclosed and the impact of differences in company practice assessed.

7.11.3. The CP58 quantitative templates do not currently appear to allow for an option table as described above, but could be added in the Level 3 guidance to be issued from 2010 onwards. 


\section{SUMMARY}

\subsection{Summary}

8.1.1. This paper has tried to present the ways in which ESG models fit into Solvency II from a high level perspective which will be accessible to senior management and the non-technical reader.

8.1.2. In section 2, the paper described some of the applications of ESG models. For example, the different regulatory regimes which use an ESG model, the financial reporting standards and the product designers in an insurer.

8.1.3. In section 3 , the paper considered market consistent valuation in some detail and asked if it was still a valid technique to use in the light of criticism. The paper has discussed how market consistent valuation is not a purely objective measure and has subjective assumptions which need to be considered. Market consistent valuation has the disadvantage of not accounting well for the microstructure of markets and also being pro-cyclical. However, is has the advantages of a good degree of objectivity, transparency and economic coherence. Under Solvency II, it will be need to be used, but it will be important to appreciate how to relate the market consistent measure to real management actions regarding the purchase and sale of assets and liabilities. This is especially important for users of internal models who will have to demonstrate that they trust the internal model to inform major decision making within the firm; i.e. that they comply with the Use Test.

8.1.4. In section 4, the paper discussed the advantages and disadvantages of using ESG models for market consistent valuation. ESG models have advantages in the primary valuation of participating life insurance liabilities through their ability to take the account of management action, policyholder actions and many underlying asset classes. Their ability to include more sophisticated economic models with fat-tails or yield curve dynamics are further advantages. Currently, the disadvantages of sampling error and runtime are outweighed by the advantages for primary valuation. In revaluation work the emphasis is on speed of calculation and replicating portfolios have been widely used for this work.

8.1.5. In section 5, the paper looked at selected aspects of the market consistent balance sheet. The valuation of assets was considered as was the coherence between asset and liability valuation. Different product types were considered and their suitability for valuation using an ESG was discussed. Finally, the risks associated with counterparty credit and their integration with the ESG were discussed.

8.1.6. In section 6, the paper discussed the role of ESG models within an internal model. The section illustrated how an ESG model is still required when using the standard formula. The internal model was then explored in some depth, particularly the internal model tests which need to be passed. The section dealt with the Use Test, Calibration Test, Statistical Quality Test, Validation Test, Documentation Test and External Providers. Documentation is a particularly important area and was treated in some detail. The section drew out the importance of the statistical quality tests and discussed how ESG models can help the calibration test to translate between risk measures. Finally, the application to partial internal models was briefly discussed.

8.1.7. In section 7, this paper explored some Pillar 2 and 3 issues. Firstly, the governance issues around ESG models. CP33 describes a number of different governance concepts and role, the most notable of which for ESG models are the Risk Management System, Risk Management Function and the Actuarial Function. It was 
explained that, from an ESG modelling perspective, the governance structure looked different and comprised producer function of Risk \& Actuarial Function, Economist Function and Technology Function. The paper tried to describe how these ESG governance functions could fit with the CP33 governance functions. Consumer Functions use ESG output were described. These included the Finance Function, Sales \& Marketing Function and Board of Directors. The paper particularly highlighted the importance of the Sales \& Marketing Function in an ESG governance function and provided some examples of how the Sales \& Marketing Function may have different ESG model requirements to the Risk and Actuarial department. Finally, the Pillar 3 issue of disclosure was briefly discussed.

\section{2. $\quad$ Further Work}

8.2.1. There is much more which could be written about the interaction of ESG models and Solvency II from a non-technical standpoint, but this paper was intended to be short to encourage wider readership so much detail has been omitted. Much could also be written about quantitative interaction ESG models and Solvency II, but this should be the subject of papers aimed at a technical audience. It is my hope that this paper has struck the right balance between useful content and a non-technical treatment which makes the issues around ESG models accessible to a senior management audience. However, the paper will inevitably fall short of this aim in some aspects. I therefore welcome comments or questions from readers, which I will do my best to answer.

\section{ACKNOWLEDGEMENTS}

\subsection{Contributors}

9.1.1. I would like to thank Russell Ward of Ernst \& Young LLP and Thorsten Pffeifer of FINMA for many useful discussions and inputs to the paper. Especially in their roles as co-authors of an earlier incarnation of this paper as a chapter in the Incisive Media publication, The Solvency II Handbook.

9.1.2. I would also like to thank Seth Eshun of the U.K. Financial Services Authority for his valuable input in developing the original slides which were the forerunner to the section on the Solvency II Handbook.

\subsection{Reviewers}

9.2.1. I would also like to thank the following people for responding to my queries during the development of this paper and for their review of the paper.

- $\quad$ Gareth Collard, Ernst \& Young LLP.

- Andy Cope, KPMG LLP.

- Andrew Hitchcox, Kiln Group.

- Søren Kruse, Aktuariebolaget.

- Craig McCulloch, KPMG Actuaries Pty Ltd.

- $\quad$ Laura Santori, Standard \& Poors.

- Bruce Porteous, Standard Life

- $\quad$ Nick Dexter, KPMG LLP

9.2.2. I would also like to thank my two scrutineers for giving up their time to read the early drafts and for their helpful suggestions. 


\subsection{Colleagues, Past and Present}

9.3.1. I have been lucky enough to work with some very knowledgable people during the course of my career and would therefore like to thank my former colleagues at Barrie \& Hibbert, Deloitte and Bacon \& Woodrow for many interesting conversations around the design, calibration and use of ESG models. Particularly John Hibbert, Phil Mowbray, Colin Wilson, Steffen Sorensen, Gavin Kretzschmar, Alex McNeil, Steven Morrison, Graeme Lawson, Andrew Smith, Frances Southall, Tim Sheldon, Stavros Christofides, Cliff Speed and Hui Ming Ng. Apologies to any others that I have missed and should have included.

9.3.2. I would also like to thank my current colleagues at KPMG for their input in improving this paper, especially around the issue of governance. Their patience in creating time for this paper to have been written has been much appreciated.

\subsection{Errors, Disclaimer and Previous Publication}

9.4.1. Any errors in the paper are entirely the responsibility of the author.

9.4.2. This paper represents the views of the author and does not make any statement about the views of KPMG LLP.

9.4.3. Some of the material in this paper has previously been published as a chapter for The Solvency II Handbook by Risk Books. 


\section{REFERENCES}

ArtZner, P., Delbaen, J., HEATH, D. Coherent Measures of Risk (1999). Available at: http://www.math.ethz.ch/ delbaen/ftp/preprints/CoherentMF.pdf.

BARRIE \& HIBBERT Liquidity Premium Literature Review http://www.barrhibb.com/documents/downloads/Liquidity_Premium_Literature_Review.PDF

BOARD FOR ACTUARIAL STANDARDS: Modelling : Exposure Draft Available at: http://www.frc.org.uk/images/uploaded/documents/Modelling\%20ED\%20Final.pdf

Brooks, D., Care, R.J., Chaplin, M.B.,. KaufmanA.M., Morgan, K.A., RoberTs, D.N., Skinner, J.M.E., Huntington-Thresher, D.J.K., Tuley, P.J. \& Wong, D.L. (2009) Actuarial Aspects of Internal Models for Solvency II Available at: http://www.actuaries.org.uk/_data/assets/pdf_file/0009/146664/sm20090223.pdf

CEIOPS Consultation Papers on Level 2 Implementing Measures (2009). Available at: CP33: http://www.ceiops.eu/media/files/consultations/consultationpapers/CP33/ CP39: http://www.ceiops.eu/media/files/consultations/consultationpapers/CP39/ CP40: http://www.ceiops.eu/media/files/consultations/consultationpapers/CP40/ CP41: http://www.ceiops.eu/media/files/consultations/consultationpapers/CP41/ CP56: http://www.ceiops.eu/media/files/consultations/consultationpapers/CP56/ CP58: http://www.ceiops.eu/media/files/consultations/consultationpapers/CP58/ CP64: http://www.ceiops.eu/media/files/consultations/consultationpapers/CP64/ CP65: http://www.ceiops.eu/media/files/consultations/consultationpapers/CP65/ CP69: http://www.ceiops.eu/media/files/consultations/consultationpapers/CP69/ CP70: http://www.ceiops.eu/media/files/consultations/consultationpapers/CP70/

Deighton, S.P., DiX, R.C., Graham, J.R., \& SkinneR, J.M.E. (2009). Governance and Risk Management in United Kingdom Insurance Companies Avalilable at: http://www.actuaries.org.uk/_data/assets/pdf_file/0009/148086/sm20090323.pdf

Frankland, R., Smith A.D., Wilkins T., VARNELL, E.M., Holtham A., Biffis, E., Eshun S., \& Dullaway D. (2008). Modelling Extreme Market Events. Institute of Actuaries. Available at: http://www.actuaries.org.uk/_data/assets/pdf_file/0007/140110/sm20081103.pdf.

Sheldon, T.J. \& SMith A.D. (2004). Market Consistent Valuation of Life Assurance Business. British Actuarial Journal 10(3): 543-626.

SOLVENCY II DIRECTIVE: http://www.europarl.europa.eu/sides/getDoc.do?pubRef=//EP//NONSGML+TA+20090422+SIT-03+DOC+WORD+V0//EN\&language=EN

STANDARD AND POORS Criteria, Insurance General, Summary of Standard \& Poor's Enterprise Risk Management Evaluation Process for Insurers http://www2.standardandpoors.com/spf/pdf/media/ERM_Evaluation.pdf

WiLMoтT P., Introduces Quantitative Finance (2001) Available at: http://www.wilmott.com 
